\title{
Sleep Disordered Breathing: An Epidemiological Study among Albanian Children and Adolescents
}

\author{
Yllka Abazi ${ }^{1, *}$, Fabian Cenko ${ }^{1}{ }^{1}$, Marianna Cardella ${ }^{2}$, Gjergji Tafa ${ }^{3}$ and Giuseppina Laganà 4 \\ 1 Department of Biomedical Science, Catholic University Our Lady of Good Counsel, 1000 Tirana, Albania; \\ f.cenko@unizkm.al \\ 2 Private Practice, 00100 Rome, Italy; cardella.marianna@gmail.com \\ 3 Private Practice, 1000 Tirana, Albania; gjergjitafa12@gmail.com \\ 4 Department of Clinical Sciences and Translational Medicine, University Tor Vergata, 00133 Rome, Italy; \\ giuseppinalagana@libero.it \\ * Correspondence: y.abazi@unizkm.al; Tel.: +355-68-40-54-554
}

Received: 6 October 2020; Accepted: 13 November 2020; Published: 19 November 2020

check for updates

\begin{abstract}
Sleep Disordered Breathing (SDB) comprises a group of diseases characterized by alterations in the frequency and/or depth of breathing during sleep. The aim of this study was to investigate the frequency of SDB in a group of Albanian children and adolescents and to describe its social, physiological, psychological, sleep-related, and anthropometric risk factors, in relation to the sociodemographic situation. A total of 6087 participants (mean age: 10.42 years, range: 6 to 15 years, $52.3 \%$ females and $47.7 \%$ males) attending public schools all over Albania took part in the cross-sectional study. On a sample of 6087 questionnaires distributed, 4702 (77.25\% of the original sample) were returned and included in the study. High risk status for SDB was assessed using the Paediatric Sleep Questionnaire (PSQ). The prevalence of SDB was 7.9\%. No statistically significant difference was found for gender at high risk for SBD. Compared to participants living in urban aeras $(7.3 \%)$, participants living in rural areas $(10.4 \%)$ reported significantly higher SDB prevalence rates. No other significant correlations were detected between the high-risk subjects and the age. The prevalence of the subjects at high risk of SBD obese participants $(20.8 \%)$ was statistically higher than among nonobese ones (6.3\%). SDB is highly prevalent in Albanian growing population and further prevalence studies are recommended.
\end{abstract}

Keywords: SDB; questionnaire PSQ-SRDB; Albanian population

\section{Introduction}

Sleep Disordered Breathing (SDB) comprises a group of diseases ranging from snoring to Obstructive Sleep Apnea (OSA), characterized by alterations in the frequency and/or depth of breathing during sleep [1]. SDB in childhood can lead to behavioral and cognitive impairments that might be related to the particular vulnerability of the pre-frontal cortex [2]. The pediatric individuals with sleep disorders present hyperactivity, restlessness, lack of attention, loss of appetite and irritability $[3,4]$. If left untreated, SDB in development age could be responsible to significant morbidity leading to metabolic syndrome [5], cardiovascular consequences [6], and growth failure [7]. The negative impact of SDB may not simply be confined to the short-term wellness and development during childhood but may continue adversely affecting during the long-term development in adulthood.

There are many risk factors that can lead to a reduction or collapse of upper airways and which may contribute to the pathogenesis of SDB. Pediatric sleep disorders are associated with at least four clinical phenotypes: Adenotonsillar hypertrophy, orthodontic and craniofacial alterations and syndromic conditions, primary neuromuscular disorders, and obesity. The emerging epidemic of 
obesity has refocused attention to this phenotype today. However, the relationship between obesity and SDB in children and adolescent is clearly conflicting.

Despite increased awareness in the adult population, SDB often goes undetected in childhood and in adolescent age. The clinical presentation of a child with SDB is usually nonspecific, requiring increased expertise of the primary care professional. The prevalence of this disorder differs from 1 to $5.8 \%$ in pediatric patients, referring to studies using accurately and objective diagnostic measures such as polysomnography and pulse oximetry $[1,8,9]$, and $4-11 \%$ based on questionnaire surveys of parents [10,11].

The gold standard diagnosis consists in polysomnography (PSG), although its utilization is not very common because it requires a "sleep medical center", which implies long time, qualified operators, high-tech devices, and high costs related to these conditions. A first step would be carrying on epidemiological studies in order to assess the prevalence of individuals at high risk utilizing specific self-administered questionnaires [12].

The aim of this study is to determine, in growing Albanian populations, the prevalence levels of SDB as a function of sex, age group, obesity, and urban/rural residence categories, and its social, physiological, psychological, sleep-related, and anthropometric risk factors. Yet, there are no reports on SDB of Albanian children and adolescents and its association with their sociodemographic factors.

\section{Materials and Methods}

\subsection{Study Population}

The target population of this cross-sectional study was composed of growing subjects; the sample covered a random sample of public schools in the largest areas of the country. The selected sample was chosen during the period October 2018-May 2019.

A special permission issued from Ministry of Education Sport and Youth (MESY) of Albania regulated the data collection. Through the MESY, the data about the total number of students in public schools for the 2018-2019 school year was obtained. A two-stage sampling strategy was applied in order to ensure the representativeness of the sample for all students attending the obligatory public schools in the country. The first stage referring to a random selection of the schools, and the second stage sampling procedure selecting the classes inside each school. The total number of participants required was proportional to the population density by district. The final sample was composed of 6087 subjects between the ages of 6 and 15, representing $4.24 \%$ of the public-school population in Albania.

In each selected school, during the first stage, the survey team delivered the relative questionnaires to the selected classes from the second stage. Then, inside each selected class, a questionnaire was handed over to attending students in order to be delivered and completed from their parents.

The questionnaire can be simplified into two parts: the first page contains demographic information (age, gender, residence) and consensus confirmation signed from the parents, respecting the privacy of personal data according to the Helsinki Declaration principles. Two trained students (Marianna Cardella and Gjergji Tafa) collected anthropometric measurements from the subjects' height $(\mathrm{m})$ and weight $(\mathrm{kg})$ using a digital scale. The BMI $\left(\mathrm{kg} / \mathrm{m}^{2}\right)$ was calculated and overweight/obesity was defined as $\geq 25 \mathrm{~kg} / \mathrm{m}^{2}$ [13]. On the second page, the 22 closed-response questions consisted of prominent symptoms of sleep disorders. The following specific criteria for exclusion have been verified for each participant before added in the final sample: previous or current orthodontic therapy, syndromes and compromised craniofacial anomalies (Figure 1). The filled and signed questionnaires were collected the next day of the delivery. 


\title{
Pediatric Sleep Questionnaire
}

(Screening)

Name of the child:

Date of birth:

Person completing this form:

Date that you are completing the questionnaire:

\begin{abstract}
Instructions: Please answer the questions about how your child IN THE PAST MONTH. Circle the correct response or print your answers in the space provided. "Y" means "yes," "N" means "no," and "DK" means "don't know." For this questionnaire, the word "usually" means "more than half the time" or "on more than half the nights."
\end{abstract}

Please answer the following questions as they pertain to your child in the past month.

1. While sleeping, does your child:

YES NO

Don't Know

Snore more than half the time?

Always snore?

Snore loudly?

Have "heavy" or loud breathing?

Have trouble breathing, or struggle to breath?

$\begin{array}{lll}Y & N & D K\end{array}$

$\begin{array}{lll}Y & N & D K\end{array}$

2. Have you ever seen your child stop breathing during the night?

Y $\quad \mathrm{N}$

DK

3. Does your child:

Tend to breathe through the mouth during the day?

Have a dry mouth on waking up in the morning?

Occasionally wet the bed?

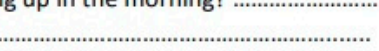

4. Does your child:

Wake up feeling unrefreshed in the morning?

Have a problem with sleepiness during the day?

5. Has a teacher or other supervisor commented that your child appears

sleepy during the day? .

6. Is it hard to wake your child up in the morning?

7. Does your child wake up with headaches in the morning?

8. Did your child stop growing at a normal rate at any time since birth? ...

9. Is your child overweight?

$\begin{array}{lll} & & \\ Y & N & D K \\ Y & N & \text { DK } \\ Y & N & \text { DK }\end{array}$

10. This child often:

Does not seem to listen when spoken to directly

Has difficulty organizing tasks and activities.

Is easily distracted by extraneous stimuli ....

Fidgets with hands or feet, or squirms in seat

Is "on the go" or often acts as if "driven by a motor"

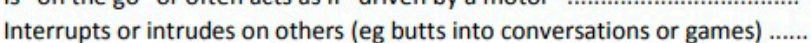

$\begin{array}{lll}Y & N & D K\end{array}$

Figure 1. Pediatric Sleep Questionnaire.

The whole process of questionnaire distribution and data collection was carried out from the same team composed from two students and one professor from Faculty of Dentistry of the Catholic University of "Our Lady of Good Counsel" in Tirana, Albania. The same University financially sustained this epidemiological study.

This study followed the principles laid down by the World Medical Assembly in the Declaration of Helsinki 2008 Helsinki Declarations on medical protocols and ethics and received positive response by the Ethic Committee at the University of Rome Tor Vergata ( $\left.n^{\circ} 139 / 2019\right)$.

\subsection{The Definition of PSQ-SDRB Scale}

Specific self-administered questionnaires could be effectively utilized to diagnose SDB and evaluate the progress of treatment. This process requires utilization of validated prospective Pediatric Sleep Questionnaire (PSQ), developed for individuals from 2 to 18 years old assessing the presence of 
specific symptoms such as snoring, apneas, sleepiness, and behavior disorders. The Pediatric Sleep Questionnaire, originally published by Chervin et al., yielded better results than other published questionnaires, reaching the sensitivity as high as $85 \%$ and specificity level as high as $87 \%$ [4].

The Sleep-Related Breathing Disorders (SRDB) scale contains 22 symptoms indicating snoring frequency, noise, observed apnea, difficulty breathing during sleep, daytime sleepiness, unreliable or hyperactive behavior, and other pediatric SDB characteristics, each of them previously correlated with polysomnography confirmed OSA in affected growing individuals. The scale score for each individual questionnaire is done by dividing the total number of questions answered in the affirmative (YES) by the number of questions answered both in an affirmative (YES) and negative (NO). In this formula has been excluded the questions with "don't know" or "don't reply" response from the numerator and denominator. The result, which is a number ranging from 0.0 to 1.0, when scoring $>0.33$ is considered positive and suggests a high risk for SDB in participants [14]. Otherwise, scale score $\leq 0.33$, define a person not at risk for SDB. The subscales within the SRDB scale include a 4-element sleepiness scale, a 4-item snoring scale, and a 6-element inattention/hyperactivity scale element originally derived from the Diagnostic and Statistical Manual of Mental Disorders (DSM-IV) and criteria for attention-deficit/hyperactivity (ADHD).

Before proceeding with the translation of the questionnaire, an official request was sent to the Author to obtain the authorization for the translation in respect to the Copyright. After having obtained the authorization, preserved in the archives of the Catholic University Our Lady of Good Council in Tirana and the University of Michigan, the subsequent phases of linguistic validation was performed [15]. This process was recommended by Beaton et al. [16], including the following steps:

1- Forward translation of the questionnaire from English into Albanian by two translators;

2- Synthesis of the two translations;

3- Back-translation;

4- Evaluation by an expert committee;

5- Pretesting of the penultimate version.

The direction of validation process was entrusted to a single project manager with the task of checking, correcting and managing the different phases.

\subsection{Statistical Analysis}

All data were analyzed with the Statistical Package for the Social Sciences software (SPSS ${ }^{\circledR} 26.0$ (IBM Corporation, Armonk NY, USA) for Apple Mac ${ }^{\circledR}$ ). Internal consistency and item-total score correlations were used for reliability analysis. Internal consistency was tested using Cronbach alpha for every sub-scale of the instrument since every sub-scale represents a different concept for the patients. Cronbach's $\alpha$ values less than 0.50 were regarded as not acceptable. The item score and total score relationships were explored by Pearson's correlation analysis. Validity of the Albanian version of the PSQ was tested by construct validity analysis. Construct validity was tested by using known group method tested by ANOVA analysis.

Descriptive statistics are presented (means and standard deviations or percentages) for quantitative and qualitative variables, respectively. PSQ scores were examined by sex, age, and region-based categories, and confidence intervals have been calculated according to Normal Approximation to the Binomial according to the Standard Normal Distribution. Correlations of PSQ scores with age were evaluated with the Spearman rank correlation coefficient (rho). The linear regression for bivariable analyses was applied using the Student $t$ distribution and $F$ distribution.

\section{Results}

On a sample of 6087 questionnaires distributed, there was a return of 4702 (77.25\% of the original sample). Out of 4702 filled-in questionnaires returned, 4442 were considered appropriately completed $(94.47 \%)$; 260 questionnaires were excluded cause of not answering all the questions (5.53\%). 
According to the division of the sample based on urban and rural residence, the urban sample was larger than the rural areas one (83\% versus $17 \%)$ : only in Tirana and Durresi, due to logistical, timing and economic issues, the sample was distributed in both residences. Regarding the district-based distribution, the subsamples from each district are not equal because they are proportional to the surveyed target population. According to INSTAT [17], Tirana represents almost half of the total sample based on its general population about one third of the whole country.

Table 1 shows the Cronbach's alpha value for snoring domain, which was 0.63 (4 items/questions). Item scale correlations for snoring domain were significant only for the questions "Does your child snore loudly" and "Does your child always snore" where the relative correlation coefficients were 0.53 and 0.51 accordingly. The remaining two questions "Does your child snore more than half the time" and "Does your child have heavy or loud breathing" the correlation coefficients were 0.32 and 0.34 , respectively.

Table 1. Internal consistency of the PSQ (Cronbach alpha values).

\begin{tabular}{cc}
\hline \multicolumn{2}{c}{ Internal Consistency of the PSQ } \\
\hline Domain & Cronbach's Alpha \\
\hline Snoring domain & 0.63 \\
Sleepiness domain & 0.38 \\
Inattention domain & 0.53 \\
\hline
\end{tabular}

For sleepiness domain, Cronbach's alpha value was 0.38. None of the singular questions were significant such as "does your child wake up feeling unrefreshed in the morning", "Does your child have a problem with sleepiness during the day", "Has a teacher o other supervisor commented your child appears sleepy during the day", and "Is it hard to wake your child up in the morning" had the following respective correlation coefficients $0.27,0.27,0.07$, and 0.21 , respectively.

Cronbach's alpha value for inattention domain was 0.53 . Item scale correlations for the items "does not seem to listen when spoken directly", "Has difficulty organizing tasks and activities" and "Is easily distracted by extraneous stimuli" were $0.29,0.25$, and 0.28 , respectively. Similarly, items "Fidgets with hands or feet or squirms in seat", is "on the go", or often acts as if "driven by a motor", and "Interrupts or intrudes on others (e.g., butts into conversations or games)" were $0.24,0.31$, and 0.33 , respectively.

Comparison of total PSQ scores between children reporting different symptom severity and duration demonstrated that PSQ score increased as the symptom severity and duration increased $(p<0.001)$ (Table 2). Total score was calculated to be $0.13 \pm 0.11$ in children who did not report severe symptoms while it was calculated as $0.4 \pm 0.18$ in children with apnea during sleep $(p<0.001)$. Similarly, total PSQ score for children that did not report snoring was $0.13 \pm 0.11$ while that for the ones who snore throughout sleep was $0.32 \pm 0.17(p<0.001)$.

Table 2. Comparison of PSQ scores between different symptom groups.

\begin{tabular}{|c|c|c|c|c|c|}
\hline \multirow{2}{*}{\multicolumn{2}{|c|}{ Type of Symptom }} & \multicolumn{4}{|c|}{ PSQ Scores } \\
\hline & & Total & Snoring & Sleepiness & Inattention \\
\hline \multirow{4}{*}{ Symptom Severity } & None & $0.13 \pm 0.11$ & $0.02 \pm 0.09$ & $0.2 \pm 0.25$ & $0.23 \pm 0.25$ \\
\hline & Loud snore & $0.35 \pm 0.17$ & $0.7 \pm 0.23$ & $0.29 \pm 0.27$ & $0.33 \pm 0.30$ \\
\hline & Difficulty breathing & $0.33 \pm 0.16$ & $0.27 \pm 0.34$ & $0.29 \pm 0.28$ & $0.38 \pm 0.29$ \\
\hline & Apnea during sleep & $0.4 \pm 0.18$ & $0.32 \pm 0.38$ & $0.32 \pm 0.27$ & $0.47 \pm 0.31$ \\
\hline$p$ value & & $<0.00$ & $<0.00$ & $<0.00$ & $<0.00$ \\
\hline \multirow{3}{*}{ Symptom duration } & Never & $0.13 \pm 0.11$ & $0.01 \pm 0.07$ & $0.2 \pm 0.25$ & $0.23 \pm 0.25$ \\
\hline & Snore $>$ half of sleep & $0.31 \pm 0.15$ & $0.57 \pm 0.26$ & $0.3 \pm 0.27$ & $0.31 \pm 0.27$ \\
\hline & Snore throughout sleep & $0.32 \pm 0.17$ & $0.68 \pm 0.26$ & $0.26 \pm 0.27$ & $0.32 \pm 0.29$ \\
\hline$p$ value & & $<0.00$ & $<0.00$ & $<0.00$ & $<0.00$ \\
\hline
\end{tabular}


Table 3 illustrates the sample distribution by residency, gender, and age.

Table 3. Descriptive data of studied sample by residence, sex and age.

\begin{tabular}{|c|c|c|c|c|c|c|c|c|}
\hline \multirow{2}{*}{ District } & \multirow{2}{*}{ Total Sample } & \multicolumn{2}{|c|}{ Residence } & \multicolumn{2}{|c|}{ Sex } & \multicolumn{3}{|c|}{ Age (in Years) } \\
\hline & & Urban & Rural & Male & Female & $6-9$ & $10-12$ & 13-15 \\
\hline Elbasani & 24 & 24 & 0 & 5 & 19 & 6 & 5 & 13 \\
\hline Tirana & 1869 & 1388 & 481 & 880 & 989 & 810 & 695 & 364 \\
\hline Durrësi & 829 & 548 & 281 & 392 & 437 & 286 & 350 & 193 \\
\hline Gjirokastra & 172 & 172 & 0 & 82 & 90 & 64 & 63 & 45 \\
\hline Saranda & 171 & 171 & 0 & 76 & 95 & 65 & 88 & 18 \\
\hline Dibra & 264 & 264 & 0 & 138 & 126 & 98 & 100 & 66 \\
\hline Bulqiza & 248 & 248 & 0 & 130 & 118 & 76 & 140 & 32 \\
\hline Shkodra & 526 & 526 & 0 & 263 & 263 & 215 & 206 & 105 \\
\hline Vlora & 339 & 339 & 0 & 154 & 185 & 115 & 130 & 94 \\
\hline Total & $4 \overline{4} 4 \overline{2}$ & $3 \overline{6} 80$ & $\overline{7} 6 \overline{2}$ & $2120^{-}$ & $232 \overline{2}$ & $\overline{1735}$ & $\overline{177 \overline{7}}$ & $\overline{930}$ \\
\hline
\end{tabular}

At the completion of the data-entry of all eligible questionnaires, $342(7.90 \%)$ subjects were considered with high risk for SBD, versus 4093 (92.1\%) of school children (Table 4). The syndrome prevalence is higher in boys that in girls (8.5\% vs. $7.2 \%)$ although this difference was not found significant $(\mathrm{t}=1.61, p$ value $=0.103)$.

Table 4. Frequency of subjects with high risk SBD (gender and residence status). ${ }^{*}$ Confidence Interval.

\begin{tabular}{ccccccc}
\hline & \multicolumn{2}{c}{ Subjects at Risk of SBD } & \multicolumn{2}{c}{ Gender } & \multicolumn{2}{c}{ Residence Status } \\
\cline { 2 - 7 } & No & Yes & Male & Female & Urban & Rural \\
\hline Number & 4093 & 349 & 2120 & 2322 & 3680 & 762 \\
Prevalence & $92.10 \%$ & $7.90 \%$ & $8.50 \%$ & $7.20 \%$ & $7.30 \%$ & $10.40 \%$ \\
$\mathrm{CI}^{*}(\%)$ & 7.1 to $8.7 \%$ & 7.3 to $9.7 \%$ & 6.1 to $8.3 \%$ & 6.5 to $8.1 \%$ & 8.2 to $12.6 \%$ \\
\hline \multicolumn{4}{c}{ * Confidence Interval }
\end{tabular}

Table 4 also describes the frequency of SDB risk according to residence status (urban versus rural) where the higher rural prevalence $(7.3 \%$ vs. $10.4 \%)$ is statistically significant $(\mathrm{t}=2.86$ and $p$-value $=0.004)$.

Table 5 shows the distribution of SDB prevalence by age, the highest value is at the age of $15(9.60 \%)$ and the lowest at the age of 7 (5.60\%). Although the prevalence in various years of age seemed variable, from a statistical point of view there is no significant predisposition to the pathology in one age rather than another (chi-square $=0.92, p$ value $>0.05$ )

Table 5. Frequency of subjects with high risk SBD by age.

\begin{tabular}{cccc}
\hline Age (in Years) & Number & Prevalence & CI (\%) \\
\hline 6 & 83 & $8.40 \%$ & 2.4 to $14.4 \%$ \\
7 & 445 & $5.60 \%$ & 3.5 to $7.7 \%$ \\
8 & 536 & $6.00 \%$ & 4.0 to $8.0 \%$ \\
9 & 671 & $7.90 \%$ & 5.9 to $9.9 \%$ \\
10 & 557 & $9.00 \%$ & 6.6 to $11.4 \%$ \\
11 & 634 & $9.00 \%$ & 6.8 to $11.2 \%$ \\
12 & 586 & $7.50 \%$ & 5.4 to $9.6 \%$ \\
13 & 425 & $8.50 \%$ & 5.8 to $11.2 \%$ \\
14 & 287 & $8.40 \%$ & 5.2 to $11.6 \%$ \\
15 & 218 & $9.60 \%$ & 5.7 to $13.5 \%$ \\
\hline
\end{tabular}


Specifically, Table 6 reports the frequency of subjects at high risk of SDB according to district residence of the sample. The distribution of subjects at high risk for SDB amongst districts varies from a minimum of $4.2 \%$ in Elbasan to a maximum of $10.5 \%$ in Gjirokastra. There is no statistical association for the geographic distribution of individuals positive to SDB (Chi-Square 9.4, $p$-value > 0.05).

Table 6. Frequency of subjects with high risk SBD per district.

\begin{tabular}{cccc}
\hline District & Number & Prevalence & CI (\%) \\
\hline Elbasani & 24 & $4.20 \%$ & 0 to $12.2 \%$ \\
Tirana & 1869 & $8.00 \%$ & 6.8 to $9.2 \%$ \\
Durrësi & 829 & $7.40 \%$ & 5.6 to $9.2 \%$ \\
Gjirokastra & 172 & $10.50 \%$ & 5.9 to $15.1 \%$ \\
Saranda & 171 & $7.00 \%$ & 3.2 to $10.8 \%$ \\
Dibra & 264 & $7.20 \%$ & 4.1 to $10.3 \%$ \\
Bulqiza & 248 & $10.90 \%$ & 7.0 to $14.8 \%$ \\
Shkodra & 526 & $5.90 \%$ & 3.9 to $7.9 \%$ \\
Vlora & 339 & $9.10 \%$ & 6.0 to $12.2 \%$ \\
\hline All sample & 4442 & $7.90 \%$ & 7.1 to $8.7 \%$ \\
\hline
\end{tabular}

Similarly, the correlation between SDB and overweight/obesity shows a greater frequency of overweighted/obese children and adolescents at risk of SDB (20.8\%) compared to normal-weighted ones (6.3\%). From the data obtained in Table 7 , it is noted that differences between groups is statistically significant (chi-square $=39.7, p$ value $<0.05)$.

Table 7. Frequency of subjects with high risk SBD per obesity.

\begin{tabular}{cccccc}
\hline \multirow{2}{*}{ BMI $\geq \mathbf{2 5}$} & \multicolumn{5}{c}{ SBD } \\
\cline { 2 - 6 } & Value & YES & \% & No & \% \\
\hline Yes & 400 & 83 & 20.8 & 317 & 79.2 \\
No & 3938 & 250 & 6.3 & 3688 & 93.7 \\
Don't know & 65 & 12 & 18.4 & 53 & 81.6 \\
No answer & 39 & 6 & 15.3 & 33 & 84.7 \\
Total & 4442 & 351 & 7.9 & 4091 & 92.1 \\
\hline
\end{tabular}

\section{Discussion}

Analyzing SDB, it should be stated that large samples, with more than 1000 subjects, make difficult the employment of both polysomnography and actigraphy. Therefore, in these cases, the questionnaires represent the most valid and easy tool, despite having limitations related to the accuracy of data due to the length of the questionnaire, the level of understanding of the questions, and the actual awareness from the parents on reporting truly required signs and symptoms attributable to SDB. The latest barriers could be limited by a clear described questionnaire to be handed to children caretakers/parents for filling them in. For the same reason, we used questionnaires that we previously tested in the University clinic and that are still applied as a diagnostic tool in the Orthodontics and Pediatric Dentistry Department. As already mentioned, the questionnaire applied in this research has been standardized and it was known its sensitivity and specificity, $81 \%$ and $87 \%$, respectively [4]. The pediatric sleep questionnaire represents a valid tool that has previously used in similar studies [18,19]. According to a recent review only this type of questionnaire has shown sufficient diagnostic precision to be used as a screening method for SDB [20].

According to our data we can confirm that the SDRB-PSQ Scale of childhood evaluating snoring, sleepiness, and inattention is a valid and reliable tool. Reliability denotes the ability of a scale to produce consistent results when completed under similar conditions, whereas validity denotes the extent to which a scale measures the construct it is supposed to. Reliability is analogous to the scale's precision, 
whereas validity is analogous to its accuracy. Similar results were found for the reliability and validity of Turkish version questionnaire [21]. That can be used to identify SDB or their associated constructs in the search clinical when polysomnography, as a golden standard, is not feasible. Furthermore, this tool identifies the high-risk status for SDB in individuals and not the confirmation the relative diagnose.

The present research concerning the issue of respiratory sleeping problems in growing population is unique in Albania. Early identification and treatment would help to prevent morbidity and complications due to SDB. In the overall sample, out of 4442 individuals, $7.9 \%$ are at risk for SDB. This prevalence falls within the range of values found in the literature as evaluated by Lumeng and Chervin, describing the risk of SDB between $4 \%$ and 11\% [1]. A study conducted by Sanchez et al. has reported a higher prevalence rate (17.7\%) of SDB in Chilean schoolchildren [22]. Baidas et al. found that $21 \%$ of children in Saudi primary school were at high risk for SDB [23].

According to INSTAT [17], approximately $41.8 \%$ of the Albanian population resides in rural areas. In general, the countries tend to have a higher population in urban areas compared to rural ones. This facilitates access to basic services, such health care or education. Consequently, the higher the ratio of urban to rural population, the higher the welfare of the inhabitants of a state. From a statistical point of view, an important significance is detected through the evaluation of prevalence according to urban and rural residence, which shows a greater frequency in the rural areas versus urban $(10.4 \%$ versus 7.3\%). Probably this is due to the unequal distribution of economic growth and wealth between rural and urban which reflects an increasing un-equality in the health status of the population, as affirmed by National Planning Cycles data (National Institute of Statistics).

This study aims to address this deficiency and to add strength to the evidence that SDB is probably prevalent in the rural population than in the urban areas.

SDB occurs in development individuals of all ages mostly during two peak periods. The first peak prevalence of OSA in children occurs between 2 and 8 years, due to pharyngeal lymphatic tissue hypertrophy [24] A second peak arises during adolescence in relation with weight gain [25]. The prevalence of SDB, distributed per each year of age, was not statistically significant, but the prevalence of individuals at risk of SDB tends to increase in adolescent period. The literature reports a higher risk rate for SDB in males, due to hormonal factors involved [26,27]; however, our study reports SDB affects children and adolescent of both sexes equally [28].

Obesity is a well-established risk factor for developing SDB. It leads to chronic, low-grade inflammation and oxidative stress because of elevated levels of the inflammatory cytokines interleukin-6, tumor necrosis factor alpha, C-reactive protein, and leptin in adolescents with moderate SDB [29,30]. In addition, obesity can increase the risk of upper airway collapse and result in sleep fragmentation, which further increases appetite. leading to weight gain and obesity [31]. Leptin, "the hormone of energy expenditure", inhibits appetite in the hypothalamus by counteracting the effects of orexigenic hormone neuro-peptide $\mathrm{Y}$ and ghrelin. It also enhances the synthesis of appetite suppressant alpha-melanocyte stimulating hormone [32]. Sleep fragmentation attenuates leptin signaling pathways in hypothalamus, leading to an increase in ghrelin to leptin ratio. This leads to uncontrolled appetite and food intake, resulting in weight gain and obesity [33]. Sleep fragmentation disrupts energy homeostasis by inducing endoplasmic reticulum stress and activating unfolded protein response in the hypothalamus, which ultimately results in weight gain [32]. These childhood problems can complicate adulthood, as severe childhood obesity is associated with adulthood obesity. Additionally, the co-morbidities of severe obesity can have lasting sequelae, such as cardiovascular, metabolic, and neurocognitive morbidities [34].

The present study also reveals that the prevalence of SDB considerably increases from $6.3 \%$ in the normal-weighted population to $20.8 \%$ in the population having BMI $\geq 25 \mathrm{~kg} / \mathrm{m}^{2}$, which means every other overweight/obese participant is at risk of having SDB. A similar result has been obtained by another study by Kohler [35], who demonstrated that the risk of SDB increased 3.5 times to obese children in comparison with non-obese ones. Even though adenotonsillectomy represents the first line of therapy for these children, several studies have reported that obesity increases the risk of persistent OSAS after surgery. Weight-loss management could be the key in the treatment of obesity-related OSAS 
in children and adolescents, especially in those that have previously performed adenotonsillectomy surgery without clinical results [36].

Study limitations. The risk of SDB was subjectively determined using Pediatric Sleep Questionnaire. Accuracy of SDB with attended or unattended overnight polysomnography is important to determine the prevalence and the severity of SDB. Furthermore, in the study population, only $72.98 \%$ of original sample was considered eligible data.

\section{Conclusions}

The present study highlights a high percentage of growing subjects at risk for respiratory sleep disorders (7.9\%), with a major prevalence in Albanian rural areas. The lack of national guidelines for prevention in general [37] and in treatment of SDB reflects the absence of awareness for this pathology amongst health specialists and in the general public. In this specific context, the orthodontists should take a crucial role due to their interception about oro-cranio-facial district during developmental age. Even if, in this study, the risk of SDB was determined using the Pediatric Sleep Questionnaire, it is a first epidemiological evaluation in Albanian growing population, in a country that needs to improve the prevention about SDB.

The orthodontist takes a fundamental position within the medical team, since a careful evaluation of craniofacial growth, occlusion, weight, the typical clinical appearance, and radiographic examinations could be applied jointly with the questionnaire concluding a diagnosis of SDB, as already highlighted in other studies reported in the literature [1].

Author Contributions: Y.A. wrote the text, F.C. and G.L. revised the text, M.C. and G.T. collected the field questionnaires and completed data-entry, Y.A., G.L. and F.C. conceptualized the methodology and FC run the statistical analyses according to analyses plan. GL has run the final English editing prof of the text. All authors have read and agreed to the published version of the manuscript.

Funding: This research was funded by Catholic University "Our Lady of Good Counsel".

Conflicts of Interest: The authors declare no conflict of interest.

\section{References}

1. Lumeng, J.C.; Chervin, R.D. Epidemiology of pediatric obstructive sleep apnea. Proc. Am. Thorac. Soc. 2008, 5, 242-252. [CrossRef]

2. Beebe, D.W.; Gozal, D. Obstructive Sleep Apnea and the prefrontal cortex: Towards a comprehensive model linking nocturnal upper airway obstruction to daytime cognitive and behavioral deficits. J. Sleep Res. 2002, 11, 1-16. [CrossRef]

3. Smith, D.L.; Gozal, D.; Hunter, S.J.; Philby, M.F.; Kaylegian, J.; Kheirandish-Gozal, L. Impact of sleep disordered breathing on behavior among elementary school-aged children: A cross-sectional analysis of a large community-based sample. Eur. Respir. J. 2016, 48, 1631-1639. [CrossRef]

4. Chervin, R.D.; Hedger, K.; Dillon, J.E.; Pituch, K.J. Pediatric sleep questionnaire (PSQ): Validity and reliability of scales for sleep-disordered breathing, snoring, sleepiness, and behavioral problems. Sleep Med. 2000, 1, 21-32. [CrossRef]

5. Ischander, M.M.; Lloyd, R.D.L., Jr. Severe paediatric obesity and sleep: A mutual interactive relationship! J. Sleep Res. 2020, e13162. [CrossRef]

6. Zaffanello, M.; Piacentini, G.; La Grutta, S. The cardiovascular risk in paediatrics: The paradigm of the obstructive sleep apnoea syndrome. Blood Transfus. 2020, 18, 217-225.

7. Bonuck, K.; Parikh, S.; Bassila, M. Growth failure and sleep disordered breathing: A review of the literature. Int. J. Pediatr. Otorhinolaryngol. 2006, 70, 769-778. [CrossRef]

8. Li, A.M.; So, H.K.; Au, C.T.; Ho, C.; Lau, J.; Ng, S.K.; Abdullah, V.J.; Fok, T.F.; Wing, Y.K. Epidemiology of obstructive sleep apnoea syndrome in Chinese children: A two-phase community study. Thorax 2010, 65, 991-997. [CrossRef]

9. Bixler, E.O.; Vgontzas, A.N.; Lin, H.M.; Liao, D.; Calhoun, S.; Vela-Bueno, A. Sleep disordered breathing in children in a general population sample: Prevalence and risk factors. Sleep 2009, 32, 731-736. [CrossRef] 
10. Spruyt, K.; O’Brien, L.M.; Macmillan Coxon, A.P.; Cluydts, R.; Verleye, G.; Ferri, R. Multidimensional scaling of pediatric sleep breathing problems and bio-behavioral correlates. Sleep Med. 2006, 7, 269-280. [CrossRef]

11. Archbold, K.H.; Pituch, K.J.; Panahi, P.; Chervin, R.D. Symptoms of sleep disturbances among children at two general pediatric clinics. J. Pediatr. 2002, 140, 97-102. [CrossRef] [PubMed]

12. Patakaa, A.; Daskalopouloub, E.; Kalamarasa, G.; Passaa, K.F.; Argyropouloua, P. Evaluation of five different questionnaires for assessing sleep Apnea syndrome in a sleep clinic. Sleep Med. 2014, 15, 776-781. [CrossRef] [PubMed]

13. Cole, T.J.; Bellizzi, M.C.; Flegal, K.M.; Dietz, W.H. Establishing a standard definition for child overweight and obesity worldwide: International survey. BMJ 2000, 320, 1240-1246. [CrossRef]

14. Chervin, R.D.; Weatherly, R.A.; Garetz, S.L.; Ruzicka, D.L.; Giordani, D.L.; Hodges, E.K.; Dillon, J.E.; Guire, K.E. Pediatric Sleep Questionnaire: Prediction of Sleep Apnea and Outcomes. Arch. Otolaryngol. Head Neck Surg. 2007, 133, 216-222. [CrossRef]

15. Abazi, Y.; Tafa, G.J.; Nastasi, E.; Pashaj, E.; Cozza, P. Linguistic validation of Pediatric Sleep Questionnaire (PSQ) for diagnosis of sleep breathing disorders in children. Rev. Stomatol. Shqip. 2018, 17, 48-59.

16. Beaton, D.E.; Bombardier, C.; Guillemin, F.; Ferraz, M.B. Guidelines for the process of cross-cultural adaptation of self-report measures. Spine 2000, 25, 3186-3191. [CrossRef]

17. Institute of Statistics (INSTAT). Available online: http://www.instat.gov.al/al/temat/treguesit-demografikëdhe-socialë/popullsia/publikimet/2019/popullsia-e-shqipërisë-1-janar-2019 (accessed on 24 September 2019).

18. Garcia, J.; Wical, B.; Wical, W.; Schaffer, L.; Wical, T.; Wendorf, H.; Roiko, S. Obstructive sleep apnea in children with cerebral palsy and epilepsy. Dev. Med. Child. Neurol. 2016, 58, 1057-1062. [CrossRef]

19. Smith, D.F.; Dalesio, N.M.; Benke, J.R.; Petrone, J.A.; Vigilar, V.; Cohen, A.P.; Ishman, S.L. Anthropometric and dental measurements in children with osbtructive sleep apnea. J. Clin. Sleep Med. 2016, 12, 1279-1284. [CrossRef]

20. Alhammad, N.S.; Hakeem, L.A.; Salama, F.S. Orofacial findings associated with obstructive sleep apnea in a group of Saudi Children. Pak. J. Med Sci. 2015, 31, 388-392. [CrossRef]

21. Yüksel, H.; Sögüt, A.; Yılmaz, Ö.; Kutluay, E. Reliability and validity of the Turkish version of the pediatric sleep questionnaire: A tool for prediction of sleep related breathing disorder. Tüberküloz Ve Toraks Dergisi. 2011, 59, 236-241. [CrossRef]

22. Sánchez, T.; Rojas, C.; Casalsb, M.; Bennett, J.T.; Gálvez, C.; Betancur, C.; Mesa, J.T.; Brockmann, P.E. Prevalence and risk factors for sleep-disordered breathing in chilean schoolchildren. Rev. Chilpediatr. 2018, $89,718-725$.

23. Baidas, L.; Al-Jobair, A.; Al-Kawari, H.; AlShehri, A.; Al-Madani, A.; Al-Balbeesi, H. Prevalence of sleep-disordered breathing and associations with orofacial symptoms among Saudi primary school children. BMC Oral Health 2019, 19, 1-8. [CrossRef]

24. Brunetti, L.; Rana, S.; Lospalluti, M.L.; Pietrafesa, A.; Francavilla, R.; Fanelli, M.; Armenio, L. Prevalence of obstructive sleep apnea syndrome in a cohort of 1,207 children of southern Italy. Chest 2001, 120, 1930-1935. [CrossRef]

25. Chang, S.J.; Chae, K.Y. Obstructive sleep apnea syndrome in children: Epidemiology, pathophysiology, diagnosis and sequelae. Korean J. Pediatr. 2010, 53, 863-871. [CrossRef]

26. Sauer, C.; Schlüter, B.; Hinz, R.; Gesch, D. Childhood obstructive sleep apnea syndrome: An interdisciplinary approach: A prospective epidemiological study of 4,318 five-and-a-half-year-old children. J. Orofacorthop. 2012, 73, 342-358. [CrossRef]

27. Brockmann, P.E.; Koren, D.; KheirandishGozal, L.; Gozal, D. Gender dimorphism in pediatric OSA: Is it for real? Respir. Physiolneurobiol. 2017, 245, 83-88. [CrossRef]

28. Redline, S.; Tishler, P.V.; Schluchter, M.; Aylor, J.; Clark, K.; Graham, G. Risk factors for sleep-disordered breathing in children. Associations with obesity, race, and respiratory problems. Am. J. Respir. Crit. Care Med. 1999, 159, 1527-1532. [CrossRef]

29. Gaines, J.; Vgontzas, A.N.; Fernandez-Mendoza, J.; He, F.; Susan, L.; Liao, D.; Bixler, E.O. Increased inflammation from childhood to adolescence predicts sleep apnea in boys: A preliminary study. BrainBehav. Immun. 2017, 64, 259-265. [CrossRef]

30. Imani, M.M.; Sadeghi, M.; Khazaie, H.; Emami, M.; Sadeghi, B.D.; Brand, S. Serum and Plasma Tumor Necrosis Factor Alpha Levels in Individuals with Obstructive Sleep Apnea Syndrome: A Meta-Analysis and Meta-Regression. Life 2020, 10, 87. [CrossRef] 
31. Kuopio Sleep Apnea Group. Sustained improvement in mild obstructive sleep apnea after a diet- and physical activityebased lifestyle intervention: Postinterventional follow-up. Am. J. Clin. Nutr. 2010, 92, 688-696. [CrossRef]

32. Hakim, F.; Wang, Y.; Carreras, A.; Hirotsu, C.; Zhang, J.; Peris, E.; Gozal, D. Chronic sleep fragmentation during the sleep period induces hypothalamic endoplasmic reticulum stress and PTP1bmediated leptin resistance in male mice. Sleep 2015, 38, 31-40. [CrossRef]

33. Spiegel, K.; Tasali, E.; Penev, P.; Cauter, E.V. Brief communication: Sleep curtailment in healthy young men is associated with decreased leptin levels, elevated ghrelin levels, and increased hunger and appetite. Ann. Intern. Med. 2004, 141, 846-850. [CrossRef] [PubMed]

34. Lo Bue, A.; Salvaggio, A.; Insalaco, G. Obstructive sleep apnea in developmental age. A narrative review. Eur. J. Pediatr. 2020, 179, 357-365. [CrossRef] [PubMed]

35. Kohler, M.J.; Thormaehlen, S.; Kennedy, J.D.; Pamula, Y.; Van den Heuvel, C.J.; Lushington, K.; Martin, A.J. Differences in the Association Between Obesity and Obstructive Sleep Apnea Among Children and Adolescents. J. Clin. Sleep Med. 2009, 5, 506-511. [CrossRef] [PubMed]

36. Andersen, I.G.; Holm, J.C.; Homøe, P. Establishing a standard definition for child overweight and obesity worldwide: International survey. Int. J. Pediatr. Otorhinolaryngol. 2016, 87, 190-197. [CrossRef] [PubMed]

37. Laganà, G.; Fabi, F.; Abazi, Y.; Nastasi, E.B.; Vinjolli, F.; Cozza, P. Oral habits in a population of Albanian growing subjects. Eur. J. Paediatr. Dent. 2013, 14, 309-313.

Publisher's Note: MDPI stays neutral with regard to jurisdictional claims in published maps and institutional affiliations.

(C) 2020 by the authors. Licensee MDPI, Basel, Switzerland. This article is an open access article distributed under the terms and conditions of the Creative Commons Attribution (CC BY) license (http://creativecommons.org/licenses/by/4.0/). 